\title{
Resource recovery and zero waste management option of slaughter house waste in Khulna city corporation of Bangladesh
}

\author{
M. N. Amin \\ Department of Environmental Science, Khulna University, Khulna, Bangladesh
}

\begin{abstract}
Presently the slaughter houses of khulna city corporation (KCC) area in Bangladesh are being used in such a way that the wastes come from these are polluting the surrounding environment such as river water, solid surface, air etc. In this circumstance, the research analyzed the management options of this slaughter house wastes and determines how this process would be suitably managed through the community participation. To fulfill the above mentioned objective, the research work was conducted through the questionnaire survey, direct observation, face-to-face interview along with the random sample collection and relevant measures of different factors. The research finding reveals that the total quantity of waste produced from these slaughter houses was 2888.45 tonnes/year. The management of this volume of waste was found as unsatisfactory by the most of the stakeholder groups due to fail of the conservation of public health and ecosystem of the local community. However, the analysis of the research data and other relevant information suggest that the potential management system such as a zero waste management of the wastes of slaughter houses in Khulna City Corporation area is possible to implement for more environmentally friendly development of the society which have the potential to resource reuse (waste-to-energy recovery) and others. Finally, the research recommended three separate designs of the conventional biomethanation plant and a potential biogas production model for these slaughter houses.
\end{abstract}

Keywords: Slaughter house, Biomethanation, Zero waste management, Energy recovery, Khulna city corporation

\section{Introduction}

Current environmental management practices aim to achieve a harmonious balance between the development of economic resources and the preservation of the environment with the ultimate goal of reaching sustainability while improving the health, ecology, safety and prosperity. This approach involves taking acceptable risks in terms of the environment, human health and the economy, an interdisciplinary activity that requires close cooperation between several scientific and engineering fields. As a result solid waste management system requires a judicious planning and implementation of all activities step-by-step through the long run guides of the total system like collection, transportation, disposal racy etc. in a systematic way. Slaughter house waste management system is a complex process involving consideration of technology, economy, financial management, public policy, equipment and availability of manpower, political will etc. On the other hand, a sound, safe and healthy slaughter house waste management should have the strong financial and technology support targeting resource recovery and zero waste management (Davis and Cornwell, 1998). The term 'Resource Recovery' is used to describe the extraction of economically useable materials and energy from wastes (Ahmed and Rahman, 2003). Resource recovery by materials conversion is the recovery of products for transformation and their use as raw materials or sources of energy, along with the harnessing of the energy released during transformation (Ahmed and Rahman, 2003). In addition, Zero waste management is the distinctive philosophical concept that vary from different aspects. Generally, Zero waste management is the techniques by which all the discarded materials are used for productive purposes through material conversion or directly use of it (Giampietro and Ulgiati, 2005). Burning or burying of wastes leads to the total loss of potential by-products. That is why waste processing and disposal has to be economical and environmentally acceptable. It needs to be noted that almost all the wastes generated by a slaughter house can be processed to obtain various products which have commercial value (Annual Report, 2001). On the contrary, the potential pollutants from those wastes, if not properly managed the major pollution problems associated with these wastes are surface and ground water contamination and surface air pollution caused by odors, dust, ammonia, and $\mathrm{H}_{2} \mathrm{~S}$ (CPCB, 1992). Consequently, manure management and other resources recovery from the slaughter house waste not only help to prevent environment pollution but also produce energy are becoming increasingly attractive. In Khulna City Corporation, there are three so called structured slaughtering house running by the authority. Animals are also slaughtered in various butcher's shops in this city. However, the large amount of waste product from this slaughter house is not in well managed condition and it is being used by some other unproductive way or dumped directly as unused materials. These wastes are mainly streaming to the open surface water body and 
polluting the overall environment there. As a result, it is causing a huge suffering for the inhabitants of this area especially for the people living near to the slaughter house. In these circumstances, Resource Recovery and Zero waste management of slaughter house waste in Khulna City Corporation has been identified as the study problem which could be the key to resolve uncovers the quantity waste produced from these slaughter houses of Khulna City Corporation and give a suitable suggestion of how to deal with these wastes targeting zero waste management.

\section{Materials and Methods}

\section{Location of the Study Area}

Khulna City is the third largest city of the Bangladesh, which is located in the southwestern part of the country. It s situated between $21^{\circ} 38^{\prime \prime}$ and $23^{\circ} 1$ "north latitude and $89^{\circ} 8^{\mathrm{P} "} \& 89^{\circ} 58^{\mathrm{P}}$ east longitude and is $16 \mathrm{ft}$ above mean sea level (Banglapedia, 2004). The city stands on the western bank of the river Bhairab. Total area of the Khulna city is $47.0 \mathrm{sq} . \mathrm{km}$.

\section{Collection \& Analysis of data and Report preparation}

Most of the important material used for the study was a set of interview schedule. Other materials such as measuring tape used to take the live weight of the animal to be slaughtered, calculating machine, photographic camera were also used. For assessing the existing management system a face to face questionnaire interview was carried out among the different stakeholder groups of the study location. In addition, the final conception was drawn after performing a specific personal site visit through out the study period (February, 2007 to September, 2007). For conducting that specific interview the stakeholder groups were separated into three groups on the basis of reconnaissance survey. For relevant data collection random sampling was applied. However, it has been fixed that $20 \%$ of total Administrator population and $10 \%$ of total other stakeholder groups (worker and surrounding people) population would be studied. In this way the sample size was 7 for the administrator, 55 for the worker group and 176 for the surrounding people.

Live weights of the animals were measured by Shaeffer's formula (McNitt, 1983). Shaeffer's formula- $W=$ $\frac{\mathrm{L} \times \mathrm{G}^{2}}{300}$ pounds, which is most useful for Zebu cattle within $5 \%$ accuracy. Where, $\mathrm{W}=$ Weight of the animal, $L=$ Length from the point of shoulder to pin bone (inch) and $G=$ Heart girth (inch). Then the live weight is converted into kilogram i.e. 1 pound $=0.45359 \mathrm{Kg}$. Total number of animals slaughtered per day was recorded by personal observation in the study period. The type of waste produced from these slaughter houses were selected by personal inspection and through interviewing different stakeholder groups. Then the weight of the different types of waste was measured using the following principle -Blood volume: Cattle: 2.5 (as \% of live weight), Goat \& Sheep: 0.6 (as \% of live weight (McNitt, 1983), Rumen content: $3.5 \%$ of the live weight (Davis, 1985). Intestine content: $15 \mathrm{~kg} / 250 \mathrm{~kg}$ live weight (Banerjee, 2005). To suggest a suitable waste dealing option, the space of the slaughter house, its surrounding environmental condition and some economic factors of the stakeholder groups were observed by personal visit. Thus, these factors were compared by using interpretation of the similar situations around the world through the literature review. Moreover, a priority index analysis was conducted on the responses of the different group of respondents on this factor through the questionnaire interview during the survey period. Finally, a suitable option which would theoretically ensure the zero waste management was selected for dealing with this waste. Then three separate designs for that option were prepared on the basis of LGED Biogas Technology Training Manual, 1999. Actually, the waste left after all the activities of slaughter house in Khulna City Corporation was treated as the materials for waste dealing design. For the calculation of Total solid, the simple random sampling of the material was performed. For total solid contain calculation first the weight of the raw waste was taken. Samples were kept on the separate tray after taking the initial weight (Triple beam balance) of each sample and placed into the chamber of the oven (Binder, made in Germany) for dryness at the time of 24-36 hours at a temperature of $60-100{ }^{\circ} \mathrm{C}$. After completing of dryness of all samples, the samples were carried out and taken the final weight of each sample. For each sample, by subtracting the final weight from the initial weight and dividing the result by the initial weight and then multiply by 100 it was determined the percentage of moisture content. The average percentage value of moisture content was taken. The total solid (TS) content value was determined by subtracting the moisture content from the value of 100 for each sample. 
Secondary data were collected from different related books, Journals from library of Environmental Science Discipline and central Library of Khulna University, Khulna, Bangladesh council for scientific and industrial research (BCSIR), Local government engineering department (LGED), Department of environment, Bangladesh (DoE), Khulna City Corporation (KCC) and Bangladesh Agriculture University (BAU). The data collected by all those process were interpreted and analyzed by using computer software like MS-excel. Finally, the report of the research was prepared in the MS-Word program of Office-XP.

\section{Results and Discussion}

\section{Waste Quantity Estimation}

Before estimating the waste quantity, the type of waste produced from those slaughter houses were selected as the estimation of waste quantity depends on its types. From the frequent personal visit and questionnaire interview, it was found that the general waste products from these centers are mainly blood, intestine content, rumen content and urine. Almost $100 \%$ respondent of each group told about these waste types. Other products which are globally treated as waste product were all brought back to the butcher's shops for selling and all of these materials have some kind of uses. In addition, during the field survey it was found that the type of animal slaughtered in these centers was generally Cattle and Goats.

\section{Live Weight of Slaughtered Animal}

The waste quantity estimation also depends on the number of animal slaughtered. This number determines the slaughter house category. Based on scale of operation, slaughter house have been classified into three categories namely, large, medium and small as given in Table 1. According to the tonnes of live weight killed per day, Khalishpur and Gollamari slaughter house is in medium category and the Rupsha slaughter house is small category slaughter house. Using the Shaeffer's formula mentioned in the methodology, average live weight slaughtered per day in Gollamari slaughter house was 40.09 tonnes. However, in Khalishpur and Rupsha slaughter house average live weight killed per day were 34.74 tonnes and 3.34 tonnes per day, respectively. On the other hand, total live weight killed per year in these three slaughter houses of Khulna City Corporation was 24469.40 tonnes.

Table 1. Classification of slaughter houses

\begin{tabular}{|l|l|}
\hline Category & Slaughtering capacity (tonnes of live weight killed per day) \\
\hline Large & Above 70 \\
\hline Medium & $15-70$ \\
\hline Small & Below 15 \\
\hline
\end{tabular}

Source: Municipal Corporation of Delhi, 1990

From Fig. 1 it can be stated that highest quantity of live weight slaughtered per day was in Gollamari slaughter house and the lowest was in Rupsha. This factor is due to the presence of big markets places adjacent to these areas.

\section{Waste Quantity}

Using the relationship stated in the methodology the quantity of the different types of waste was estimated. The total waste produced from the slaughter house of Khulna City Corporation was 2889.58 tonnes per year (e.g. Blood, Intestine and Rumen content). Actually, the highest amount of waste produced from the Gollamari slaughter house and the amount was 1466.485 tonnes/year. From khalishpur and Rupsha, the amount of waste produced were 1297.63 tonnes/year and 125.45 tonnes/year, respectively.

From the Fig. 2 it can be easily remarked that the lowest waste producer was the Rupsha slaughtering house and the highest was Gollamari. In fact, the waste production difference between Gollamari and Khalishpur slaughter house was very small. 


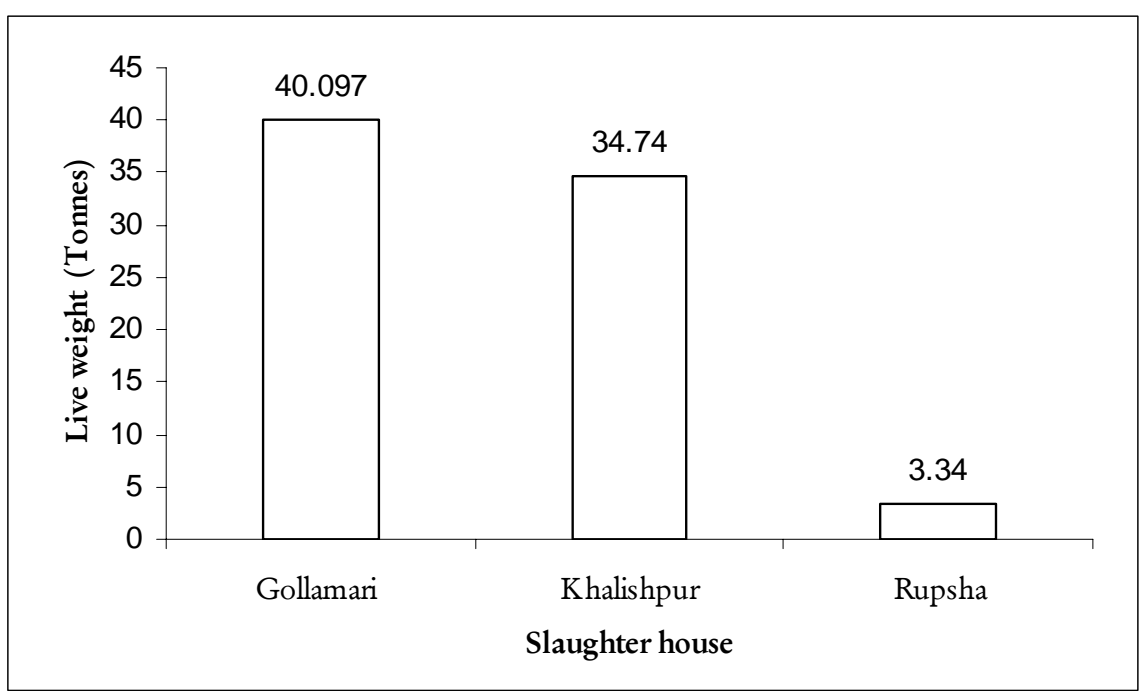

Fig. 1. Live weight of animals slaughtered per day in different slaughter houses

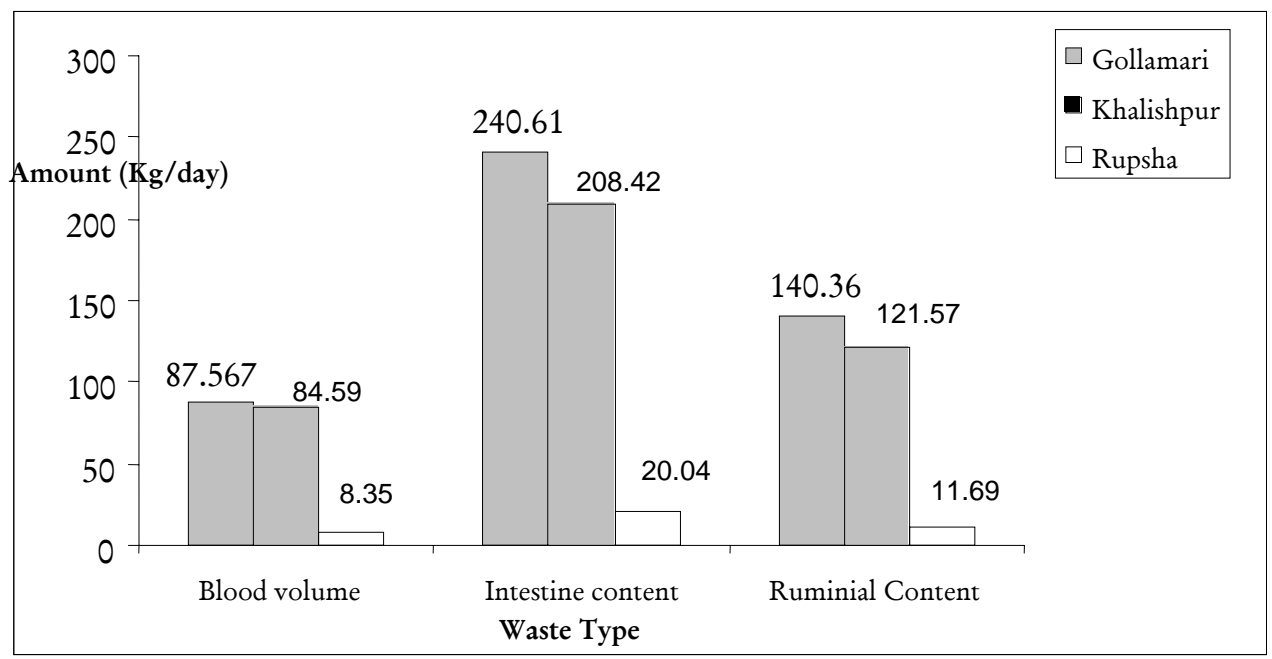

Fig. 2. waste production in three slaughter houses of Khulna City Corporation (T Page-8)

\section{Problems of Existing Management}

During the field visit problems found in different location was mainly bad odor problem, unhygienic condition and water pollution problem. In khalishpur and Rupsha area the main problem found was the odor problem. However, the problem found in Gollamari was the water pollution of the river Mayur. Unfortunately, eutrofication is the prominent feature of this river and one of the main contributors of inputs for this situation is the slaughter house waste. Yet, the problem faced by different stakeholder groups in and around the slaughter houses which was found through the face to face questionnaire interview (Table 2) is enumerated below:

In khalishpur slaughter house about $79.5 \%$ respondent told about odor problem, $59.7 \%$ stated on unhygienic environment and about $45.5 \%$ claimed on blockage in the sewerage line. In Gollamari about $89.8 \%$ told about the water pollution problem, $22.3 \%$ responded on Unhygienic environmental situation, $32 \%$ claimed on odor problem. However, in Rupsha slaughter house $79 \%$ responded on odor problem, $26.6 \%$ claimed on Unhygienic environment and $13 \%$ clamed on scarcity of pure water. Therefore, it is well executed that the main problem in two slaughter house was odor problem and in Gollamari the main problem was water pollution. In fact, this difference of problems has some meaning. 
Table 2. Existing management problem at different slaughter houses of Khulna city Corporation

\begin{tabular}{|l|c|c|c|}
\hline \multirow{2}{*}{ Management Problems } & \multicolumn{3}{|c|}{ Slaughter House Location } \\
\cline { 2 - 4 } & Khalishpur (\%) & Gollamari (\%) & Rupsha (\%) \\
\hline Bad odor & 79.5 & 32 & 79 \\
\hline Unhygienic & 59.7 & 22.3 & 26.6 \\
\hline Sewerage line block & 45.5 & --- & --- \\
\hline Water pollution & --- & 89.8 & 13 \\
\hline
\end{tabular}

Actually, Khalishpur and Rupsha slaughter house is meters away from the river. Therefore, the liquid waste needs to travel a long distance than the other one. At the time of traveling through the municipal drain it spread the bad smell all over the adjacent areas. On the other hand in Gollamari the slaughter house is situated on the bank of the dead river Mayur that has no flow. Though this river is one of the essential sources of water for the people of that area and waste discharge from this slaughter house is directly dumped into it. So, it is causing much harm to the main water sources here. Therefore, the main problem here due to the waste dumping of slaughter house was water pollution.

\section{People's Perception on the Management System}

From the questionnaire interview it was found that about $85.71 \%$ of the authority personnel responded on improvement of the total waste management system here and rest of the $14.29 \%$ thought that the existing management system is enough. Among the worker 90.9\% thought about the improvement need and rest $8.1 \%$ was satisfied on the total system. Among the people living there, $92.04 \%$ wanted the improvement of the system and rest $7.96 \%$ have no comment about improvement (Table 3). From the worker group, $85 \%$ of the respondent claimed on the occupational health safety and the rest of them response negative. From them $55 \%$ told about the lack of good practices $30 \%$ spoke about not supplying the safety equipments, $10 \%$ claimed on cleaning equipments and the rest $5 \%$ spoke on other problem of the management system.

Table 3. People's Perception on the Management System

\begin{tabular}{|l|c|c|c|}
\hline \multirow{2}{*}{$\begin{array}{l}\text { Management } \\
\text { Improvement }\end{array}$} & \multicolumn{3}{|c|}{ Slaughter House Location } \\
\cline { 2 - 4 } & Authority (\%) & Worker (\%) & Others (\%) \\
\hline Required & 85.71 & 90.9 & 92.04 \\
\hline Not Required & 14.29 & 8.1 & 7.96 \\
\hline
\end{tabular}

\section{Priority to Different Applicable Methods of Management}

For the determination of these priority only one hundred respondents from different respondent group was selected. This selection was in random basis form the total sample. When the respondents were asked about priority wise different applicable methods for dealing with the slaughter house waste, top priority was given to conventional biomethanation (Biogas plant) and the following was improved biomethanation, then composting. However, the fourth priority was improving the conventional method. Finally, the method rendering was in the last priority. The priority response for different management system of slaughter house waste is shown in Table 4.

Table 4. Priority to Different Applicable method of dealing with the slaughter House waste

\begin{tabular}{|c|c|c|c|c|c|c|c|c|}
\hline \multirow[b]{2}{*}{ Applicable method } & \multicolumn{8}{|c|}{ Priority } \\
\hline & $\begin{array}{l}\text { No } \\
(0)\end{array}$ & $\begin{array}{l}1^{\text {st }} \\
(1)\end{array}$ & $\begin{array}{c}2^{\text {nd }} \\
(0.75)\end{array}$ & $\begin{array}{c}3^{\text {rd }} \\
(0.50)\end{array}$ & $\begin{array}{c}4^{\text {th }} \\
(0.25)\end{array}$ & $\begin{array}{c}\text { Total } \\
\text { Frequency }\end{array}$ & $\begin{array}{l}\text { Priority } \\
\text { index }\end{array}$ & Rank \\
\hline Incineration & 0 & 4 & 6 & 26 & 72 & 100 & 0.325 & $\mathrm{VI}$ \\
\hline Composting & 28 & 10 & 46 & 12 & 4 & 100 & 0.515 & III \\
\hline Improved Biometanation & 26 & 14 & 44 & 12 & 4 & 100 & 0.54 & II \\
\hline Conventional Biomethanation & 26 & 20 & 48 & 6 & 0 & 100 & 0.59 & I \\
\hline Rendering & 18 & 0 & 0 & 28 & 54 & 100 & 0.275 & VII \\
\hline Improved Conventional practices & 46 & 12 & 38 & 4 & 0 & 100 & 0.425 & IV \\
\hline Only dumping to the disposal site & 40 & 14 & 14 & 32 & 0 & 100 & 0.405 & $\mathrm{~V}$ \\
\hline
\end{tabular}

Note: (Priority index is calculated for each facility by multiplying each priority with its relative weight given in the parenthesis and dividing by summation of the frequency) 


\section{Dealing Option and Design}

According to the overall situation aspect, literature review and the priority responses of the different groups in and around the slaughter house the dealing option of this waste could be the Conventional fixed Drum biogas plant. Thus, the design view of Conventional Fixed drum Biogas plant is given in Table 5

\section{Estimated Biogas Production}

In fact, to estimate the biogas production from this kind of wastes needs a precise and detailed experiment for a long time. However, we can roughly estimate the biogas production from these slaughter house waste considering all the waste as cattle dung. The model production rate is presented in Table 6.

Table 5. The design view of Conventional Fixed drum Biogas plant at three different slaughter houses in Khulna City Corporation

\begin{tabular}{|l|c|c|c|}
\hline \multirow{2}{*}{ Conventional Fixed Drum Biogas Plant } & \multicolumn{3}{|c|}{ Slaughter House Location } \\
\cline { 2 - 4 } & Khalishpur & Gollamari & Rupsha \\
\hline Total Waste & $414.58 \mathrm{~kg} / \mathrm{day}$ & $467.57 \mathrm{~kg} / \mathrm{day}$ & $40.08 \mathrm{~kg} / \mathrm{day}$ \\
\hline Dry Matter Content & $18.10 \%$ & $18.02 \%$ & $18.03 \%$ \\
\hline Digester Chamber Dimensions & 4.71 meter & 4.9 meter & 2 meter \\
\hline Hydraulic chamber Dimensions & 3.1 meter & 3.3 meter & 1.323 meter \\
\hline
\end{tabular}

Table 6. Expected biogas production from different slaughter houses of Khulna City Corporation

\begin{tabular}{|l|c|c|c|}
\hline \multirow{2}{*}{ Estimated Biogas Production } & \multicolumn{3}{|c|}{ Slaughter House Location } \\
\cline { 2 - 4 } & Khalishpur & Gollamari & Rupsha \\
\hline Total Waste & $414.58 \mathrm{~kg} /$ day & $467.57 \mathrm{~kg} /$ day & $40.08 \mathrm{~kg} / \mathrm{day}$ \\
\hline Dry Matter Content & $74.62 \mathrm{Kg}$ & $84.16 \mathrm{Kg}$. & $7.214 \mathrm{Kg}$. \\
\hline Biogas & $\mathbf{8 . 9 5} \mathbf{~ m}^{\mathbf{3}}$ & $\mathbf{1 0 . 0 9 9} \mathbf{~ m}^{\mathbf{3}}$ & $\mathbf{0 . 8 6 5} \mathbf{~ m}^{\mathbf{3}}$ \\
\hline
\end{tabular}

[N. B. Here, total possible yield of biogas per $\mathrm{kg}$ of fermentation material

$\left(Y_{p} \mathrm{KgM}\right)=0.12 \mathrm{m3} / \mathrm{kg}$ which is the lowest of all substance (LGED, 1999).]

Table 6 shows that the highest biogas production possibility is in Gollamari slaughter house. Moreover, the production possibility of Gollamari and Khalishpur slaughter house is almost similar. On the other hand the production possibility of Rupsha slaughter house is very low comparing to the other. Therefore, this data really draws the potentials of the waste-to-resource recovery targeting zero waste management of the slaughter house waste in Khulna City Corporation.

\section{Conclusion}

It is an irony of fate that the waste which has great potential is causing huge sufferings for the adjacent community of Khulna City Corporation. However, establishment of the resource recovery and zero waste management technology of slaughter house waste alike other developed countries of the world could help a lot to overcome this situation. Adoption of this method for solid waste management will improve sanitation in and around slaughter houses and it is also beneficial to the slaughter houses in long run due to returns on account of recovery and use or sale of the secondary by-products. On the other hand, it can also contribute to the natural environmental improvement and may help in improved alternative solution of the slaughter house waste management. As this type of research is new in Bangladesh, therefore, in this context, this study could be regarded as a primary ladder to reach such apex of environmental application. In fact, the study definitely supports the fact that the waste produced from these slaughter houses has a great potential for resources recovery targeting zero waste management. From the study, it is sure that the waste quantity produced from slaughter houses could be use for biogas production. In contrast, the sludge comes after gas production could be use as fertilizer after aeration. However, a largescale study is a crying need in this sector, which could be followed by a precise chemical experiment of the waste quality for finding out the specific opportunity. And this will help in future environmental impact mitigation for the more ecologically sustainable development of the large urban areas of Bangladesh. 


\section{References}

Ahmed, M.F. and Rahman, M.M. 2003. Water Supply and Sanitation- Rural and low-income urban communities. ITN - Bangladesh, BUET, Dhaka, Bangladesh. 259 pp..

Annual Report. 2001. Department of Animal Husbandry and Dairying, Ministry of Agriculture, Govt. of India, New Delhi. 13 pp.

Banerjee, C.J. 2005. A Text Book of Animal Husbandry. New Delhi-110001.

Banglapedia 2004. National Encyclopedia of Bangladesh. Asiatic Society of Bangladesh, Dhaka, Bangladesh. 23 pp.

CPCB Report. 1992. Comprehensive Industry Document: Slaughter house, meat and seafood processing industry. COINDS/38/1992. Central Pollution Control Board, Delhi. 34-39 pp.

Conservancy department of Khulna City Corporation. 2007. Personal communication with the conservancy office.

Davis, L.E. 1985. Using animal by-products in formula feeds. National Renderers Association, London, England.

Davis, L.M. and Cornwell, A.D. 1998. Introduction to Environmental Engineering. MacGraw- Hill Book Company, Inc. 251 pp.

Giampietro, M. and Ulgiati, S. 2005. An integrated assessment of large-scale biofuel production. Critical Review in Plant Sciences, 24: $22-23$.

KCC. 1999. City Development strategy (CDS) of Khulna city in context on national and city perspectives. Khulna City Corporation, Bangladesh.

LGED. 1999. Training manual on Biogas Technology (Bengali manual). In, Chakraborti, S. K. (ed.) Project on production and Use of Biogas and Organic fertilizer for Maintaining Environmental Balance Project, Local government engineering Department (LGED), Dhaka, Bangladesh.

McNitt, I.J. 1983. Livestock Husbandry Techniques, Granada Publishing Ltd. London.

Municipal Corporation of Delhi. 1990. Delhi Techno-economic Feasibility Report for Modernization of Slaughter House at Idgah. Delhi, India. 32-33 pp. 